\title{
A REVIEW PAPER ON QUANTITATIVE ASSESSMENT OF SOLAR PV SYSTEM IN JAIPUR
}

\author{
Mr. Kishan Khatri ${ }^{1}$ Dr. Shweta Choudhary ${ }^{2}$ \\ ${ }^{1} P G$ Student (Sustainable Design), Vivekananda Global University, Jaipur \\ ${ }^{2}$ Associate Professor (Centre Head CODE), Vivekananda Global University, Jaipur
}

Article DOI: https://doi.org/10.36713/epra7508

DOI No: 10.36713/epra7508

\begin{abstract}
The aim of research is to identify a performance gap of solar PV through the quantitative assessment. In the recent studies it has been observed that the actual performance is considered based on the overall irradiation on the major portion of the area, as the irradiation for low distance grade is challenging to collect across the globe. The study and analysis of the actual solar PV system is the open ground to study and benchmark the generation for particular Jaipur City. On the basis of cost analysis, it has been observed, the rooftop solar plant is a feasible solution as it provides a helping hand to meet the growing energy demand. Although, some challenges such as inflation rate, the current discount rate and life of the plant will remain with installation and generating but, can be mitigated with its long-term benefits. The current market scenario with low cost of renewable technology the role of other financial parameters affects the financial viability of the project therefore it is necessary to analyse all the parameters carefully before installing a PV plant especially in areas where land cost is a considerable parameter.
\end{abstract}

KEYWORDS: Solar PV Generation, Jaipur Radiation, Photovoltaic, Kilowatt peak, Rajasthan Solar

\section{INTRODUCTION}

This document introduces with study the need of actual performance and energy generation by solar PV system in Jaipur City. The analysis shall include measurements of various sites in Jaipur city and the comparison with the theoretical values and calculative values of energy generation.

India as a tropical country has a huge potential of harnessing solar radiation. A $3000 \mathrm{~h}$ of yearly shine received by the country every year which contributes to 4-7 kW h of solar radiation per sqm. The following factors are responsible for variation in solar radiation:

1. The intensity of solar radiation reaching the earth's surface depends on dust, moister, orientation of the sun.

2. Lakes, Mountains and oceans different intensity of solar radiation as compared to the land areas adjacent to it.
3. Daily rotation yearly declination of the sun with respect to earth shows the variation in the intensity of radiation i.e. more solar radiation during morning and afternoon.

4. Some artificial acts like smokes from forest fires and urban air pollution, also reduce the amount of solar radiation reaching the surface of the earth. Also, some radiation's scattered towards the earth called diffuse solar radiation.

Rajasthan, a state of India receives highest intensity of solar radiation with minimum rainfall throughout the year. Rajasthan has around 208,110 Sq.km of desert land. Hence, Rajasthan has more than 325 sunny days in a year having solar radiation nearly about 6-7 $\mathrm{kW} \mathrm{h/sq-m/day.} \mathrm{The} \mathrm{average}$ variation of direct normal insolation from $1800 \mathrm{~kW}$ $\mathrm{h} / \mathrm{m} 2$ to $2600 \mathrm{~kW} \mathrm{h/m2}$. Rajasthan also have lest population density which amount to abundant land for solar PV Installation. 


\section{EPRA International Journal of Research and Development (IJRD)

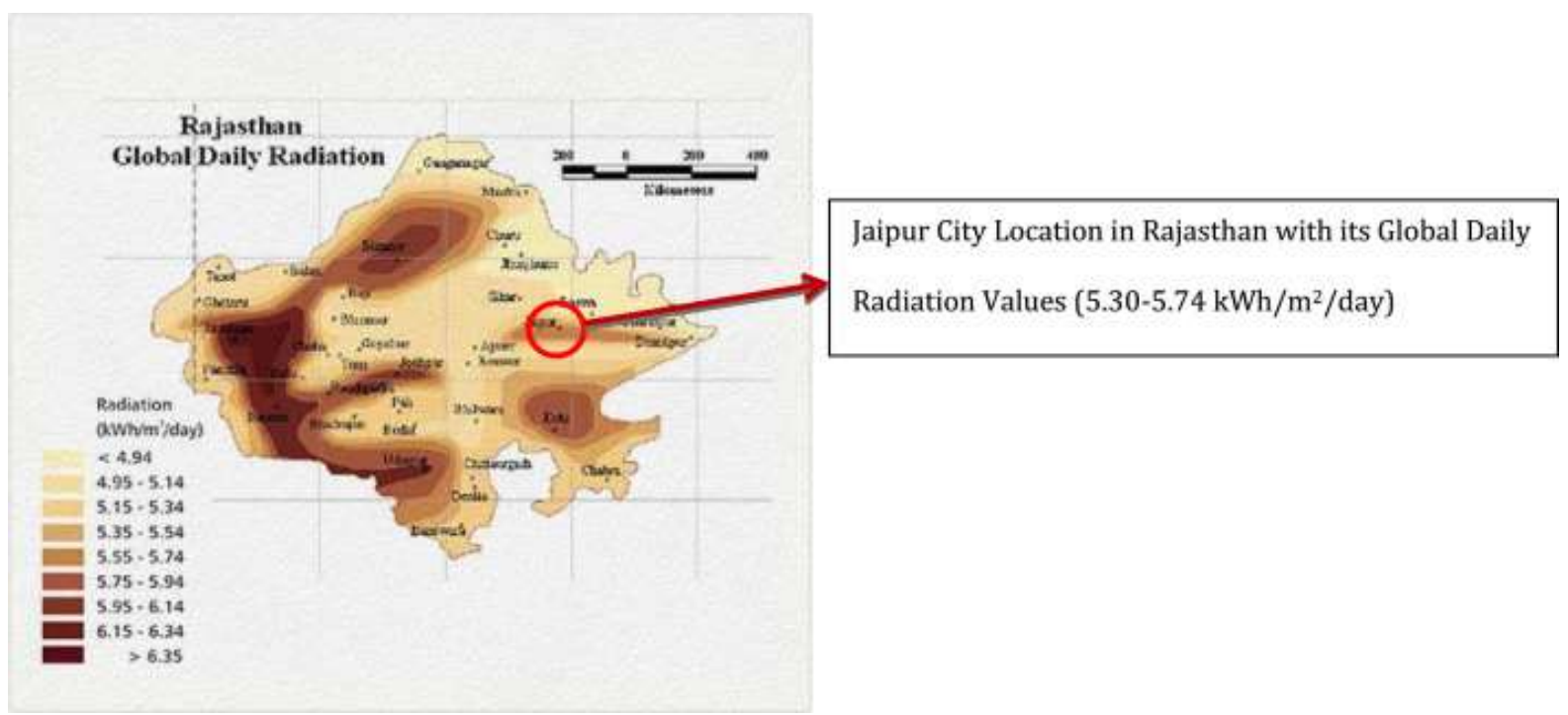

Figure 1 Radiation in Rajasthan

Source: Government, Rajasthan Solar Energy, Bureau of Investment Promotion in Rajasthan.

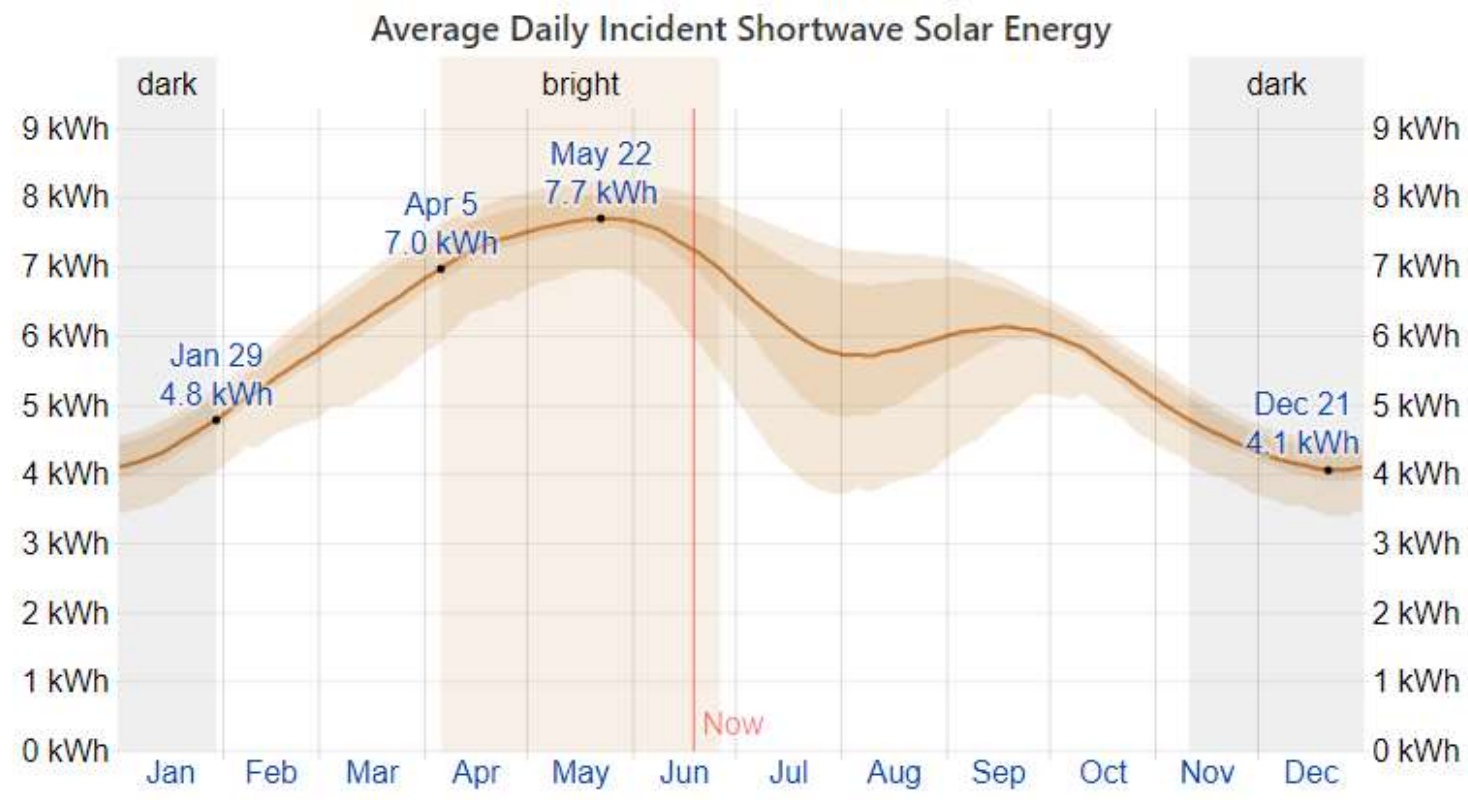

The average daily shortwave solar energy reaching the ground per square meter (orange line), with 25 th to 75 th and 10 th to 90 th percentile bands.

Source:https://weatherspark.com/y/108316/Average-Weather-in-Jaipur-India-Year-Round.

\section{LITERATURE REVIEW}

Various type of studies are being conducted to analyse the demand and cost effectiveness of potential solar photovoltaic power plant. A research by Chandel $\mathrm{M}$ et.al. [1] was done on the technoeconomic analysis of solar photovoltaic power plant for a garment zone of Jaipur city. In this study, the demand of factory was identified, the area requirement was estimated. The rate of return was further checked for onsite and offsite powerplant.
Another similar study was done by Khatri $\mathrm{R}$ [2] on design and assessment of solar PV plant for girls hostel (GARGI) of MNIT University, Jaipur city. The energy demand in one of the girl hostel was identified, financial assessment was also analysed. The inflation was introduced to check the actual payback period. After considering the inflation rate of $7.23 \%$, the revised payback period was 13.4 years.

In order to check the design parameter, an optimum angle for getting the maximum solar radiation was studied by Kumar $\mathrm{S}$, et.al. [3]. This 
study was conducted on optimum tilt angle for solar PV panel in Jaipur. The study was carried out in the month of May \& June and measurements were taken twice a week. This study revealed that optimum angle for may was $5^{\circ}-10^{\circ}$ and for June it was $5^{\circ}+/-2^{\circ}$.

To further analyse in detail, a study was done by Jayswal V K et.el. [4], on Simulation and Optimisation of a Solar Panel. HOMER tool was introduced to conduct the analysis. The total Net Capital Cost (NCV) and the cost of energy was analysed and compared which revealed that there was a huge potential in making the campus independent to the grid connectivity.

Mohanty S, et.al. [5], forecasted the solar energy in India with Survey and the implications. The forecasting is closely related to the weather forecast predictions. Accurate measurement of solar radiation for a particular location is always necessary for creating an ideal solar infrastructure.

Bhandari and Singh [6] present an analytical research of mean monthly efficiency of a flat plate collector with varying the solar Irradiation for Almora district of Uttarakhand. Monthly solar radiation data for a period of 2010-2011 used to find the average efficiency of a flat plate solar collector. Winter season has the minimum efficiency of the solar collector due to less solar irradiation.

Bano T, et.al. [7] has evaluated a performance of $1 \mathrm{MW}$ solar PV power plant which was located in Phagi, Jaipur. Performance parameters such as Performance ratio, reference yield, array yield, final yield of array are calculated using three different methods: namely Excel sheet, PV-syst, System Advisory Model (SAM). The plant performance was almost close to what calculated by SAM and PV syst method.

Nallapaneni e.t al. (2019) [8] studied and degradation, performance and energy loss a $22 \mathrm{KW}$ solar PV installed at Chandigarh in the Northern part of India. The PV syst simulation tool was used for identifying loss and yarly power generation for yearround conditions. A yearly power generation of 292954 kWh was estimated with a energy loss, PR and CF of $26.5,77.27$ and $16.72 \%$ respectively. The possible LID, and DR of the system obtained as $2.5 \%$ year $5 \%$. whereas CF is Capacity factor; PR is Performance factor; LID is light induced degradation $\&$ DR is degradation rate.

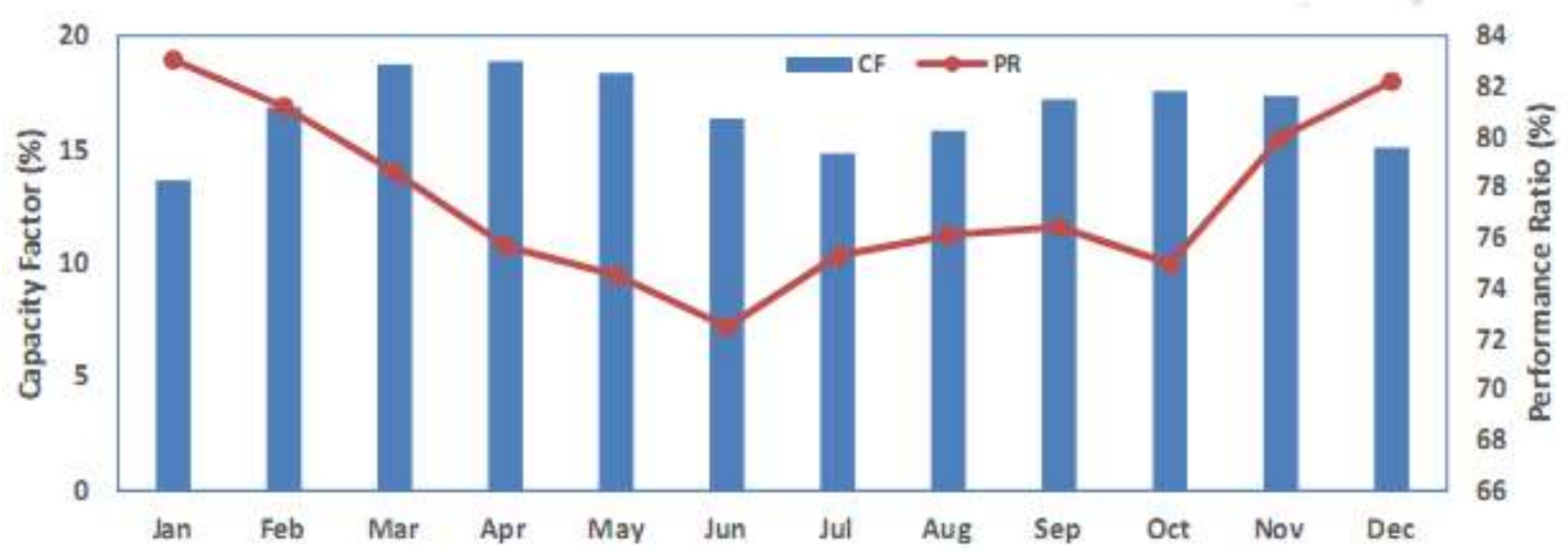

Figure 2 : Capacity factor and performance ratio

Source:https://weatherspark.com/y/108316/Average-Weather-in-Jaipur-India-Year-Round.

Vinod e.t al. (2018) [9], performed study on MATLAB software to analyse the performance of Solar PV system in a real time climate condition of India. They observed the simulated result is around $1.65 \%$ which is quite good result between the manufacturer value and simulated values. It has also presumed as a well-made tool to assess the performance of solar PV modules.

Naveen et. Al. [10], used Battery energy storage (BES) and real time implementation of SPV to compensate reactive power for supplying active power to the local grid system. The combined operation of SPV and BES is investigated to sure that voltage profile of the distribution system is improved. A real time (OPAL-RT) simulator was used to deliver active power capability of BES and SPV for improved voltage profile. 


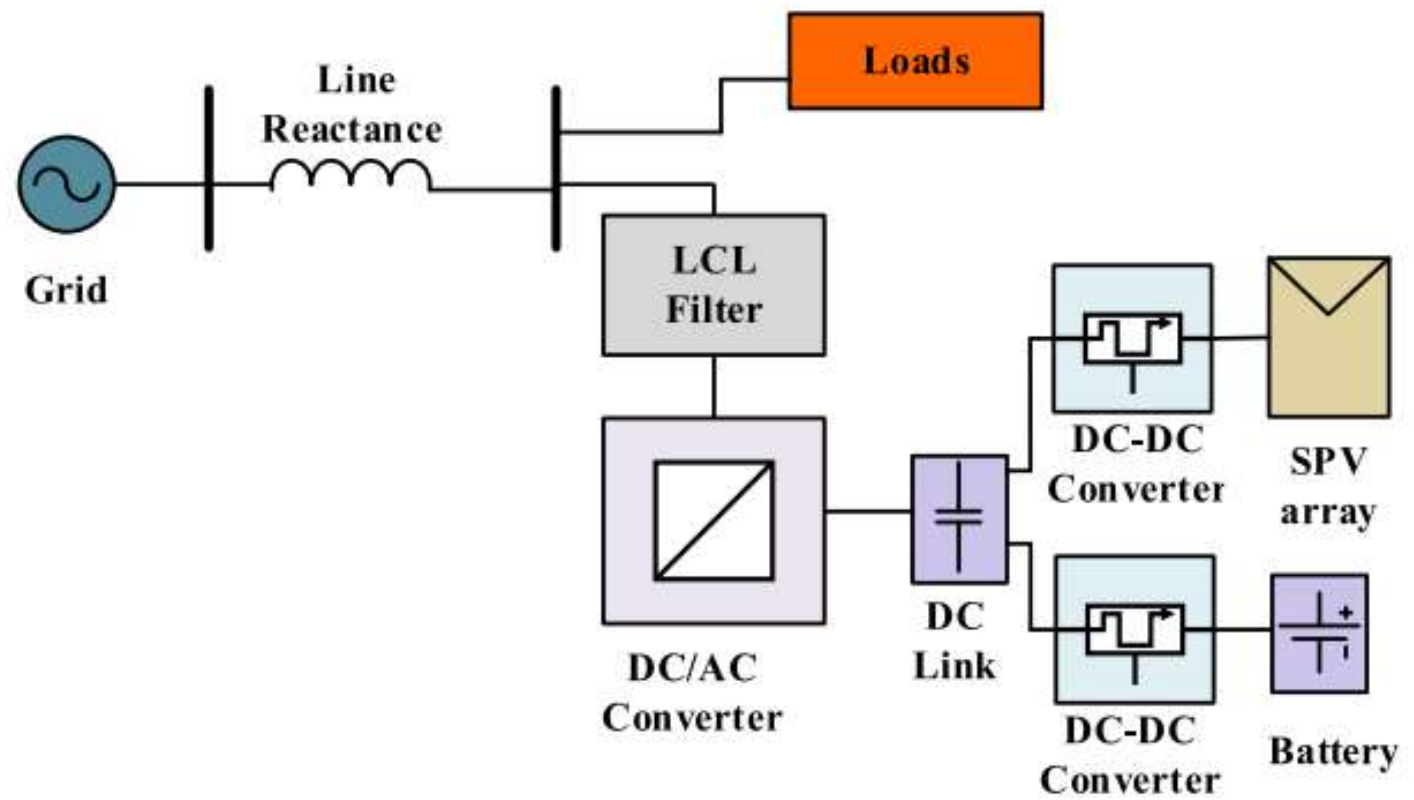

Figure 3 : Block diagram of the complete test setup

Ali et. Al.[11], studied a 30-kW rooftop solar PV system of 116 polycrystalline modules with 20degree azimuth angle and a tilt of 12 degree. A comparative analysis was done to obtain the deviation of real time generation with respect to the simulation output. The capacity factor and performance ratio were observed as $17.35 \%$ and $83.61 \%$ respectively. A displacement of 23.5 tons of $\mathrm{CO} 2$ emissions form solar PV system as compared to the conventional powerplant was also the key observation on the analysis for the year 2018 .

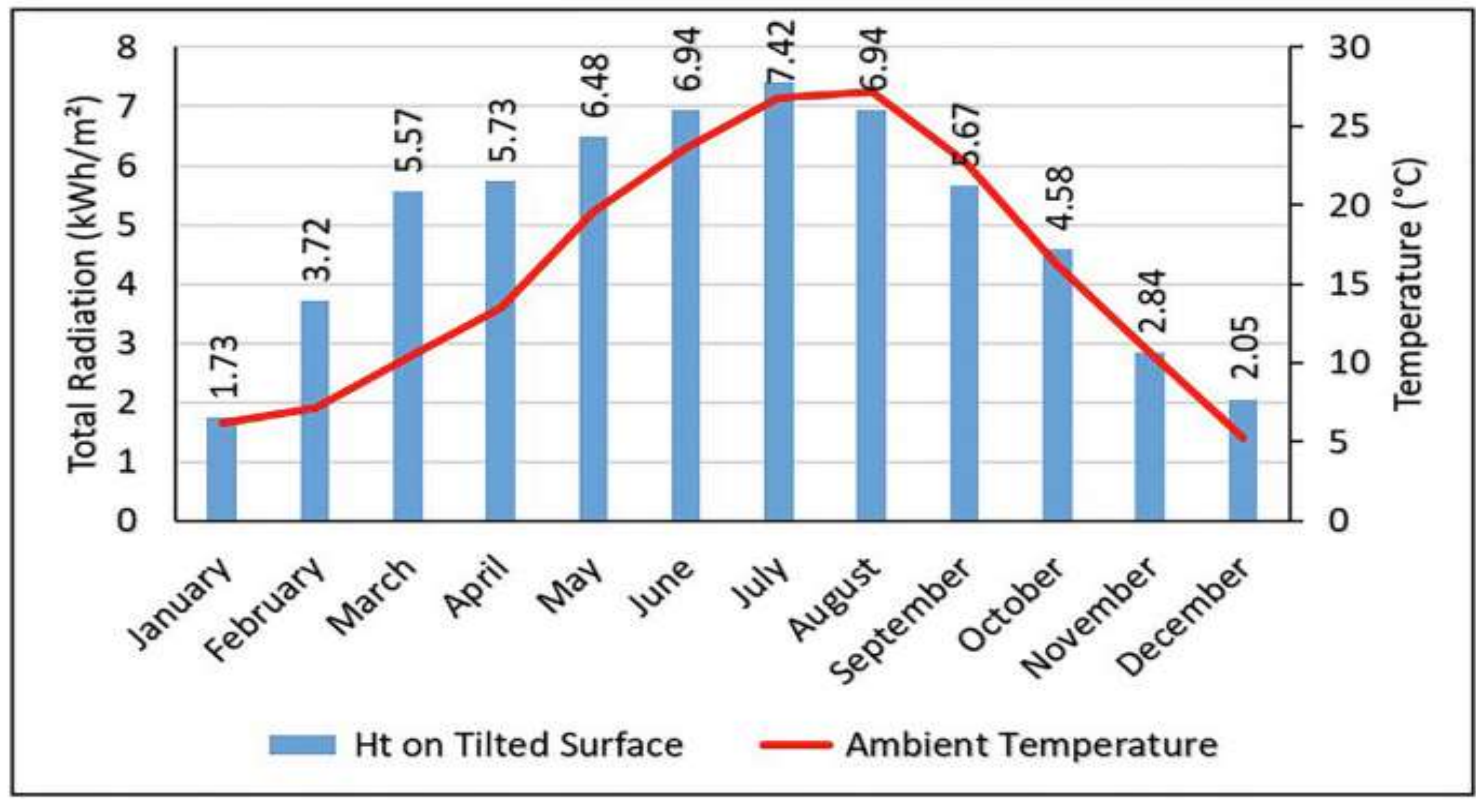

Figure 4 Monthly average daily total radiation on tilted surface and monthly average ambient temperature measured.

Source:https://weatherspark.com/y/108316/Average-Weather-in-Jaipur-India-Year-Round. 
Ajith et. Al. [12], carried out the operational performance of $2 \mathrm{MWp}$ solar PV plant in south India. The PV average utilization factor (CUF) and performance ratio $(\mathrm{PR})$ is $73.4 \%$. from June to august, which are part of the southwest monsoon season was the most deficit generation for the PV plant due to rain-dominated monsoon tropical climates. The result amounted to $35 \%$ reduction in overall energy generation from the annual average generation.
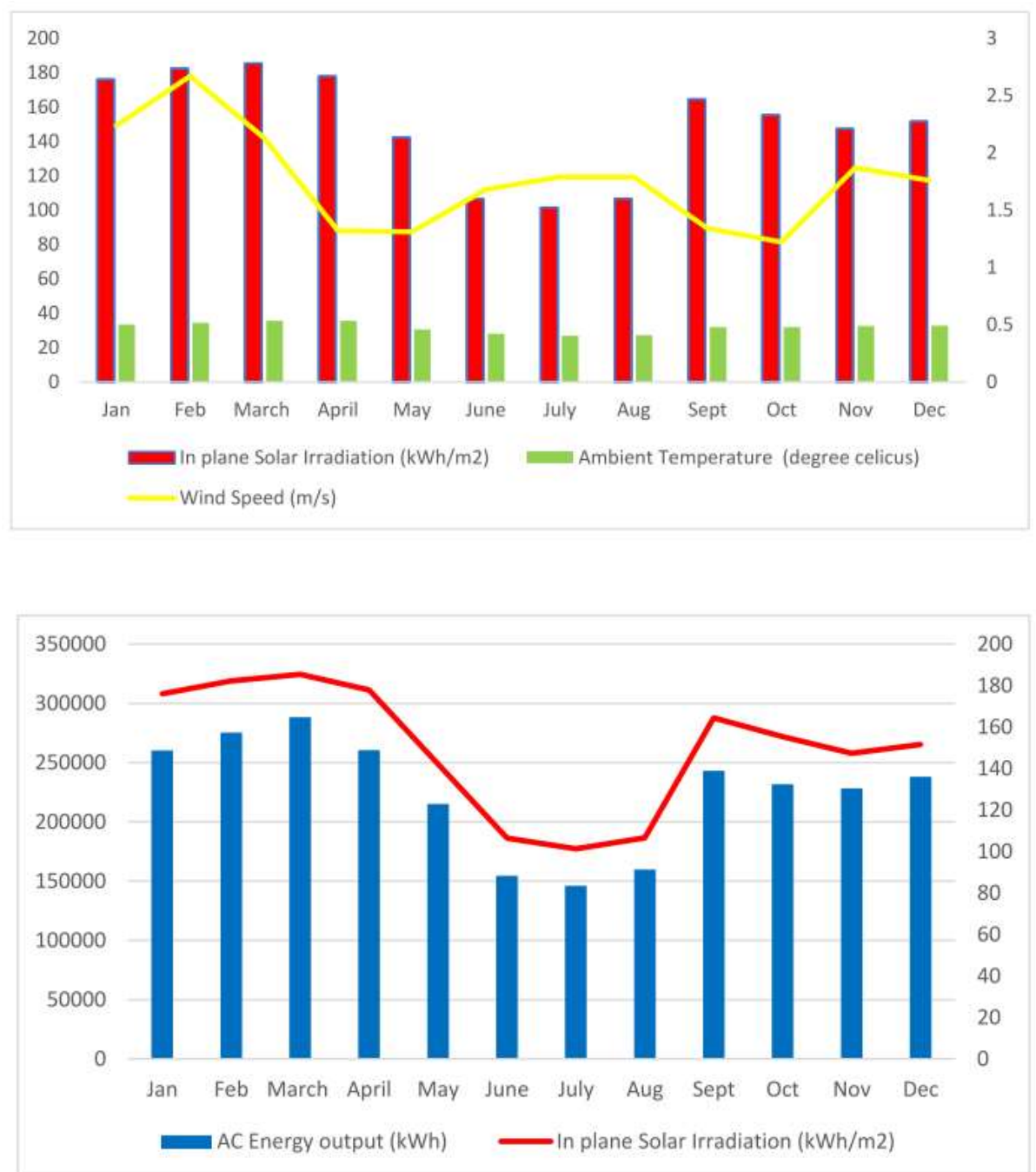


\section{EPRA International Journal of Research and Development (IJRD)}

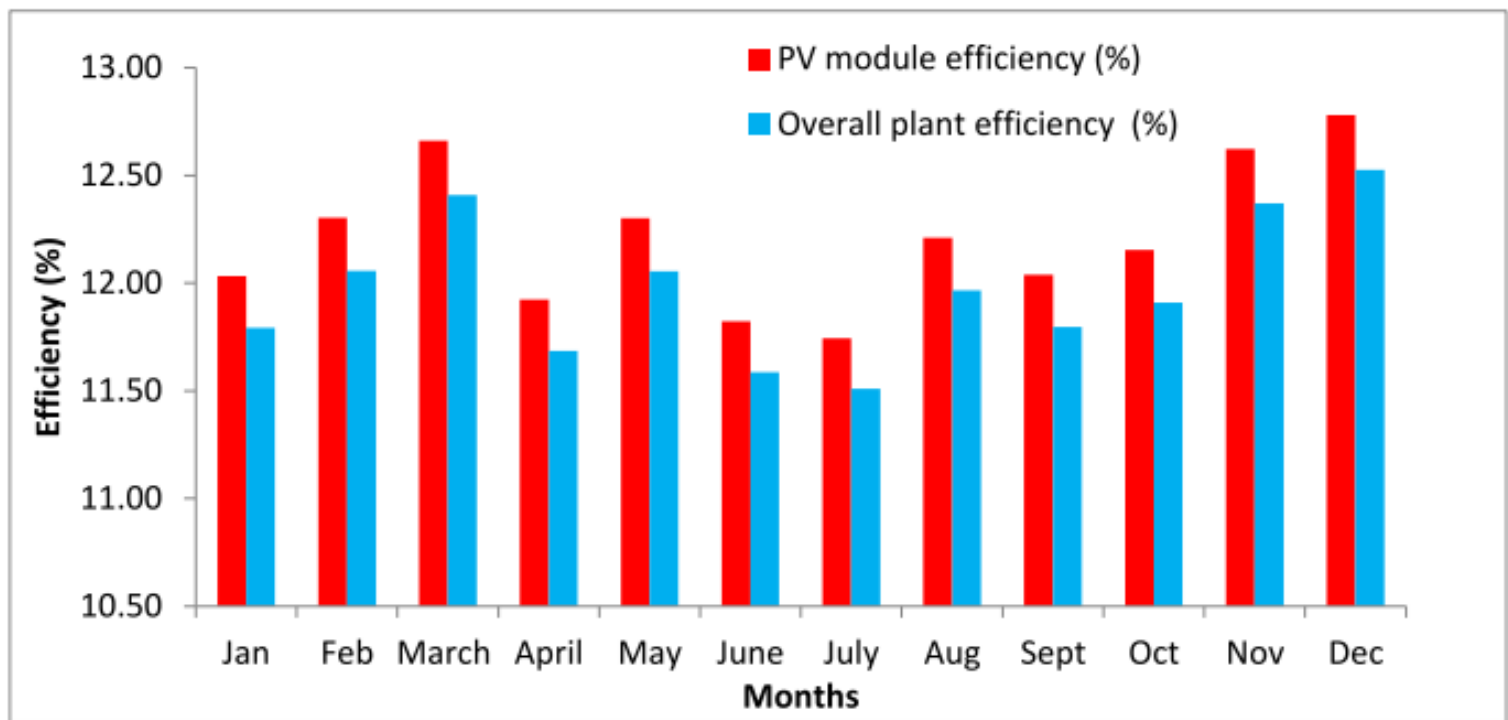

Figure 5 Monthly variation of several factors during reference year Source:https://weatherspark.com/y/108316/Average-Weather-in-Jaipur-India-Year-Round.

Subhash et. Al. [13], evaluated the performance in local climates and it is observed that experimental performance is better by generating 703 more units than theoretical generation. From experimental method, $1.09 \%$ more modules and area, are required to compensate the losses while in theoretical method $2.14 \%$ more modules and area, are required. Experimental annual PR is $56 \%$ while theoretical PR is 55\%. Therefore, material and temperature dependent losses cannot be estimated by same approach also the type of module technology to be utilized is highly site dependent.

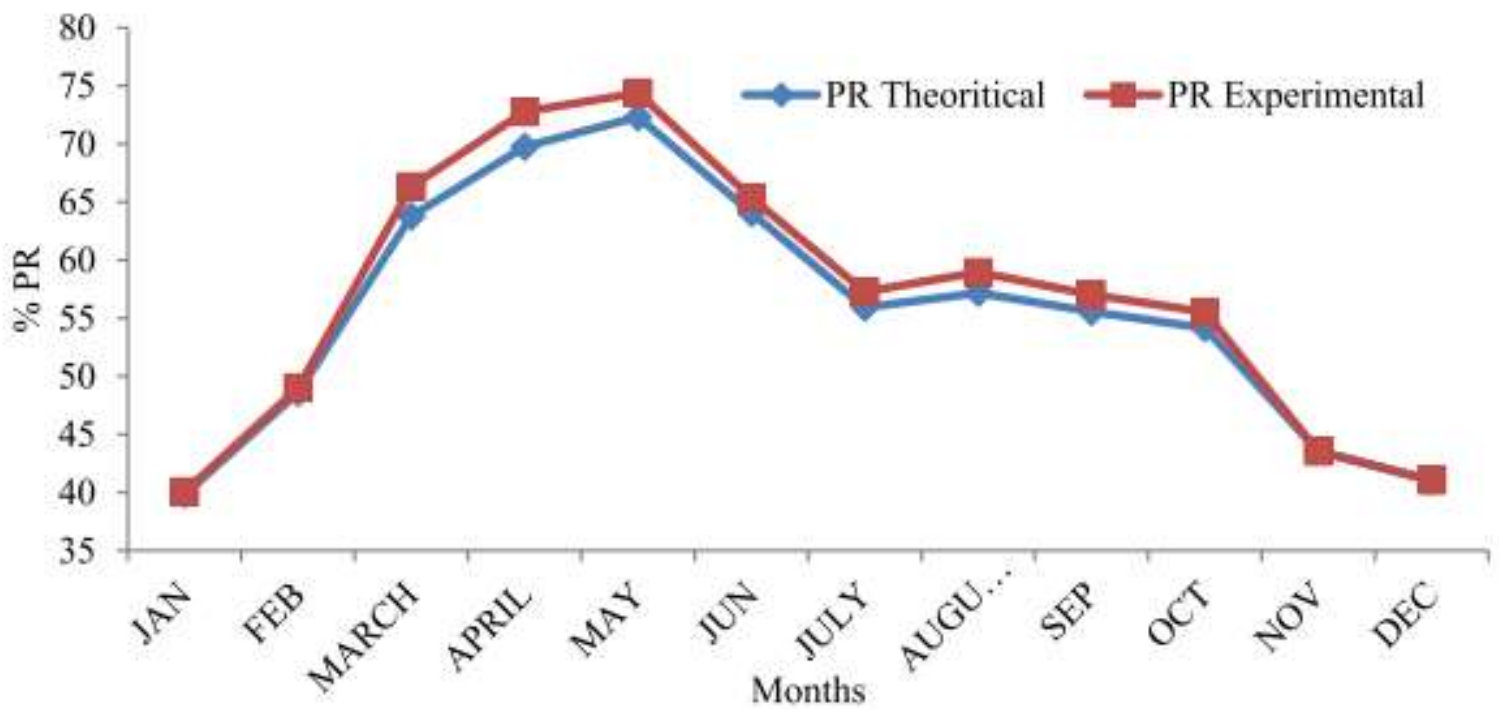

Figure 6 Performance ratio variation in different methods.

Source:https://weatherspark.com/y/108316/Average-Weather-in-Jaipur-India-Year-Round.

Subhra Das [14], conducted the short term forecasting of solar radiation and power output of $89.6 \mathrm{kWp}$ solar PV plant. As we know solar forecasting is an essential tool in solar PV power plant to improve quality of energy delivered to grid. Root mean square error (RMSE) and Forecast Score (FS) has been used to for accessing the quality of forecasting models. The proposed model for prediction of solar radiation on tilted surface is 
simple and has very high accuracy. The proposed model is compared with smart persistence model \& ARIMA model and it has been observed that it has better RSME and forecast score than both smart persistence model and ARIMA model for both $15 \&$ 30 minutes' time horizon.

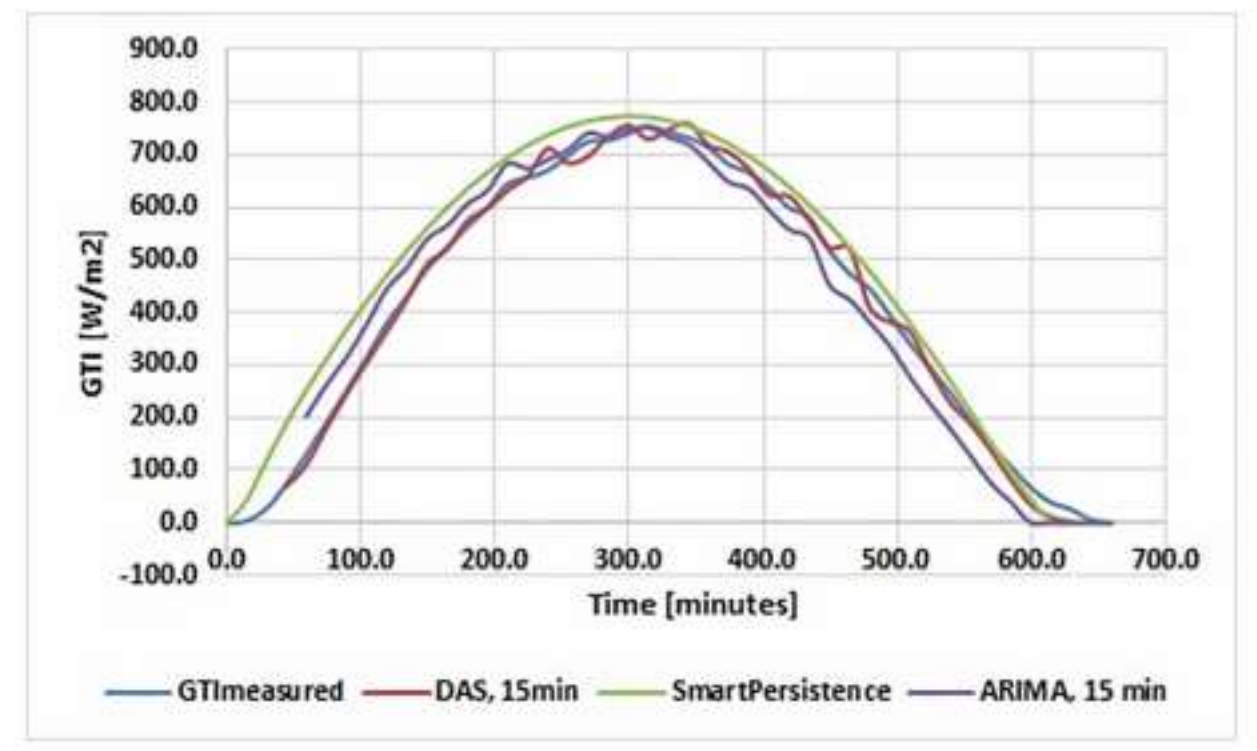

Figure 7 Comparison of measured versus predicted global solar radiation Source:https://weatherspark.com/y/108316/Average-Weather-in-Jaipur-India-Year-Round.

\section{RESEARCH GAP}

Most of the prior studies on the performance of PV power plants are carried out for finding the main performance metrics of solar PV plants installed in different geographical locations. Even though some of the studies are conducted in different climates, no serious effort was made to study the impact of weather, especially the influence of the tilt angle, dust deposition and high temperature on utility-scale PV power plants. Despite the largest intensity of solar radiation during the summer months, a lot of PV power plants are being generating less power. In order to fulfil the research gap and to understand the performance loss due to above mentioned factors, a detailed study on the performance of utility-scale PV power plants in a composite climate, Jaipur (North West Part of State Rajasthan) is carried out.

\section{MATERIALS AND METHODS}

The studies based on the analytical and measured outcomes of the solar PV plant at different climatic condition resulted to comparative analysis based on the following mathematical correlations:

\section{Calculation of the efficiencies}

The Instantaneous PV module efficiency $\left(\mathrm{y}_{\mathrm{PV}}\right)$ was calculated using equation (1),

$\mathrm{\eta}_{\mathrm{PV}}=\left[\mathrm{P}_{\mathrm{m}} / \mathrm{I}_{\mathrm{t}} \mathrm{A}_{\mathrm{m}}\right] 100$
$\mathrm{P}_{\mathrm{m}}$ is module output power,

$\mathrm{I}_{\mathrm{t}}\left(\mathrm{W} / \mathrm{m}^{2}\right)$ is total inplane solar insolation and $\mathrm{A}_{\mathrm{m}}$ is the area of module.

\section{Monthly and annual electrical energy production}

Hourly electric energy production of the PV system was calculated

$\mathrm{Eh}=\mathrm{G}_{\mathrm{t}} \mathrm{A}_{\mathrm{m}} \mathrm{y}_{\mathrm{m}} \mathrm{C}_{\mathrm{m}}$

Here $G_{t}$ is the total irradiance on module surface in an hour,

$\mathrm{A}_{\mathrm{m}}$ is the PV module area,

$\mathrm{y}_{\mathrm{m}}$ is the module efficiency and

$\mathrm{C}_{\mathrm{m}}$ is the number of modules

\section{Performance ratio}

This is the ratio of the energy that a PV plant can deliver to the grid to the energy that it can theoretically generate at STC conditions.

$\mathrm{E}_{\mathrm{AC}}=$ Produced $\mathrm{AC}$ energy during the considered time [kWh]

$\mathrm{y}_{\mathrm{STC}}=$ System efficiency at standard test conditions

$(\mathrm{STC})_{\mathrm{Gt}}=$ Irradiation at the solar module area during the considered time [kWh]

$\mathrm{PR}=100\left[\mathrm{E}_{\mathrm{AC}} / \mathrm{n}_{\mathrm{STC}} * \mathrm{Gt}\right]$

$\mathrm{EAC}, \mathrm{a}=$ Annual AC energy delivered to the grid $(\mathrm{kWh})$

$\mathrm{PPV}$, rated $=$ rated $\mathrm{PV}$ power $(\mathrm{kW})$. 


\section{Capacity factor}

The capacity factor is an indicator that demonstrates the performance of a PV system according to the installation location and the type of installation. This value is calculated by dividing the annual AC energy produced by the system to the maximum energy that the system can produce as a result of its operation at rated power for one year

$\mathrm{CF}=100\left[\mathrm{E}_{\mathrm{AC}}, / \mathrm{PPV}_{\text {rated }} * 8760\right]$

$\mathrm{EAC}_{\mathrm{a}}=$ Annual AC energy delivered to the grid (kWh)

$\mathrm{PPV}$, rated $=$ rated $\mathrm{PV}$ power $(\mathrm{kW})$.

\section{RESULTS AND DISCUSSION}

On the basis of cost analysis, it has been observed, the rooftop solar plant is a feasible solution as it provides a helping hand to meet the growing energy demand. Although, some challenges such as inflation rate, the current discount rate and life of the plant will remain with installation and generating but, can be mitigated with its long-term benefits. The current market scenario with low cost of renewable technology the role of other financial parameters affects the financial viability of the project therefore it is necessary to analyse all the parameters carefully before installing a PV plant especially in areas where land cost is a considerable parameter.

The studies showed that polycrystalline PV system for composite weather conditions like Jaipur seems to be a promising solution with minimum estimated performance of $77 \%$ with degradation rate of be 5\%/year. The simulation tools such as MATLAB, Simulink, PV-syst are also generate very precise results which agrees with manufacturer values with the maximum relative error percentage is found $1.65 \%$. A typical observation for the rainy season was obtained from a study for a $2 \mathrm{MWp}$ Utility-scale PV system for warm and humid climate zone of India in Kuzhalmannam, in the Palakkad District of Kerala, South India. The PV plant's average performance ratio (PR) is 75.02, with an average of $15.63 \%$ capacity utilization factor (CF) over the study period. The annual generation from the PV Plant is $2701467 \mathrm{kWh}$, with an average daily generation of $7420.780 \mathrm{kWh}$. The electricity generation during the summer months is highest because of the higher solar radiation during the season in this region. The electricity generation during winter months is also reasonably good because of the cleaner atmosphere and moderately lower temperature. System and capture losses are lower in rainy months, obviously due to lesser generation and solar radiation which is quite low as compared to dry climate of the country.

One of the comparative analysis of $2.5 \mathrm{MW}$ solar PV power installation at Jaipur city with and without battery bank revelled that for off-site SPV power plant is more promising as no battery required as all the power generated is supplied to the grid simultaneously and a centralized inverter is used with a step-up transformer also financial analysis shows that the off-site PV power generation option is better because of land scarcity near the city.The above analysis also concluded the to obtain maximum power density, single or double axis tracker should be preferred. However, due to financial or maintenance limitations If it is not possible than so one can fix the panel to optimal angle and get the maximum power. As this study also pointed out that for the optimum tilt angle month of May and June is $5^{\circ}-10^{\circ}$ and $5^{\circ}-2^{\circ}$. Additionally, the annual average inverter, module and overall system efficiency values of the plant were found to be $97.88 \%, 13.59 \%$ and $13.29 \%$ respectively.

\section{CONCLUSION}

The study and analysis of the actual solar PV system is the open ground to study and benchmark the generation for particular Jaipur City. In the recent studies it has been observed that the actual performance is considered based on the overall irradiation on the major portion of the area, as the irradiation for low distance grade is challenging to collect across the globe. Graphical representation of deviation in actual onsite solar energy generation depicts the substantial deviation of is consistent throughout the site in Jaipur. This deviation could be of multiple reasons which can be studied further for more accuracy. Although, some challenges such as inflation rate, the current discount rate and life of the plant will remain with installation and generating but, can be mitigated with its long-term benefits. The current market scenario with low cost of renewable technology the role of other financial parameters affects the financial viability of the project therefore it is necessary to analyse all the parameters carefully before installing a PV plant especially in areas where land cost is a considerable parameter.

\section{REFERENCES}

1. Chandel $M$ et al., Techno-economic analysis of solar photovoltaic power plant for garment zone of Jaipur city, 2014.

2. Khatri R, Design and assessment of solar PV plant for girls hostel (GARGI) of MNIT University, Jaipur city, 2016

3. Kumar S, Singh HK., Experimental Study of Optimum Tilt Angle for Solar PV Panel in Jaipur (Rajasthan), 2015.

4. Jayswal V K., simulation and optimisation of a solar panel: a case study for Suresh Gyan Vihar University Campus, 2014.

5. Mohanty S, Forecasting of solar energy with application for a growing economy like India: Survey and implication, 2017. 
6. Bhandari and Singh, Performance analysis of flat plate solar air collectors with and without fins, 2012.

7. Bano T., Performance analysis of $1 M W$ grid connected photovoltaic power plant in Jaipur, India, 2017.

8. S. Nallapaneni Manoj Kumar, "Performance, energy loss, and degradation prediction of roof-integrated crystalline solar PV system installed in Northern India," Case studies in thermal energy, vol. 100409, 2019.

9. Vinod, "Solar photovoltaic modeling and simulation: As a renewable energy solution," Energy Reports, pp. 701-712, 2018.

10. Naveen. G. \&. A. k. Dahiya, "Solar PV-BES in distribution system with novel technique for $D C$ voltage regulation," Engineering Science and Technology, and International Journal, 2020.

11. Ali Murat Ates, "Rooftop solar Photovoltaic (PV) plant - One year measured performance," Journal of King Saud University-Science, vol. 101361, p. 33, 2021.

12. Ajith Gopi, "Energy analysis of utility scale PV plant in the rain dominated tropical monsoon climates," Case studies in Thermal Engineering, vol. 101123, p. 26, 2021.

13. M. Subhash \& B. Govinda Somani, "STRINGENCY ANALYSIS OF BUILDING ENVELOPE ENERGY CONSERVATION MEASURES IN 5 CLIMATIC ZONES OF INDIA," in 14th Conference of International Building Performance Simulation Association, Hyderabad, India, 2015.

14. S. Das, "Short term forecasting of solar radiation and power output of $89.6 \mathrm{kWp}$ solar PV power plant," Materials Today: Proceedings, 2020. 